\title{
CONDOMÍNIOS RESIDENCIAIS HORIZONTAIS FECHADOS NA REGIÃO METROPOLITANA DE SÃO PAULO
}

\author{
THE DESIGN OF GATED COMMUNITIES IN SÃO PAULO METROPOLITAN AREA
}

\author{
LEMOS, João Rett \\ Estudante de graduação da Faculdade de Arquitetura e Urbanismo da Universidade de São Paulo \\ (FAUUSP) e pesquisador vinculado ao Projeto Quapá (Quadro do Paisagismo no Brasil) / Laboratório \\ da Paisagem do Departamento de Projeto. Bolsista em Iniciação Científica da Fundação de Amparo \\ à Pesquisa no Estado de São Paulo (Fapesp) \\ E-mail: joaolemos@usp.br
}

MACEDO, Silvio Soares

Professor titular de Paisagismo da Faculdade de Arquitetura e Urbanismo da Universidade de São Paulo (FAUUSP) e coordenador do Projeto Quapá - Quadro do Paisagismo no Brasil e do Laboratório da Paisagem.

E-mail: lapquapa@usp.br

\section{RESUMO}

Este trabalho tem como objeto de estudo o entendimento da formação de um tipo de paisagem urbana habitacional com características expressivamente contemporâneas, disseminada em um número expressivo de cidades brasileiras, em especial em torno da capital paulista: a dos condomínios horizontais destinados às camadas de média e alta renda.

A constatação de que se trata de um modelo de apropriação do solo urbano e, logo, de um tipo de configuração de uma paisagem, vinculado desde meados da década de 1970 aos ajustes internos promovidos no mercado imobiliário e, do ponto de vista urbanístico, aos padrões de crescimento da mancha urbana da região metropolitana de São Paulo, principalmente no que se refere ao seu processo de dispersão, suscita a necessidade de se precisar suas qualidades e suas particularidades que tornaram este tipo de empreendimento um dos motores atuais de desenvolvimento da região.

Foram analisados 28 empreendimentos lançados na região metropolitana entre 1994 e 2005, período de significativo crescimento. $O$ conjunto de estudos de caso abarca tanto os condomínios inseridos nas zonas rurais quanto nas urbanas; em comum, está o fato de serem formas de parcelamento da propriedade privada, concebidas por um empreendedor privado, e de gestão do espaço interno através de uma estrutura de decisão condominial, submetida a normas próprias.

A análise se desenvolveu em duas escalas. Num primeiro momento, restringiu-se nos espaços internos, nos quais foram identificados os padrões de arruamento e de ocupação e volumétricos dos lotes, a distribuição das áreas livres e de conservação, os equipamentos de uso comum e sua distribuição; no seguinte, a paisagem vizinha ao condomínio, identificando as características principais do tecido urbano e do ambiente natural não construído.

Palavras-chave: Condomínios fechados L, tipologias L, áreas livres.

\begin{abstract}
This paper has as study object the formation of a kind of residential urban landscape spread in a large number of Brazilian cities, in special those around the Sao Paulo metropolitan area: the gated communities destined to a population with average and high income.

The premise that it deals with a type of appropriation of urban ground related since the middle of the 1970's when internal adjustments in real estate market were implemented, and to the standards of growth of the São Paulo metropolitan area, specifically its process of dispersion, excites the necessity of identify the characteristics and specially the effects to the rest of the urban space that are been spread in terms never seen.
\end{abstract}


Twenty eight enterprises launched between 1994 and 2005 in the metropolitan area are analyzed. The set of case studies involves from communities settled in the rural zones to the urban areas; in common is the fact that are enterprises created by a private entrepreneur to subdivide an only one private property, and the management of the internal space by proper codes.

The analysis was developed in two scales: at a first moment, it was restricted in the internal spaces, appointing the planning methods and the distribution standards of the open areas, the volumetric occupations, and the leisure equipments; in the following one, were analyzed the neighbor landscape, identifying the main characteristics of the fabric urban and the not constructed natural environment.

\section{Key words: Landscape types $L$, gated communities $L$, open areas.}

\section{Introdução}

Nas duas últimas décadas observou-se na região metropolitana de São Paulo o crescimento vertiginoso do número de condomínios horizontais fechados, um tipo de moradia produzida em um nicho do mercado imobiliário residencial que atende a consumidores de um universo oriundo das camadas de média e alta renda. Promovendo transformações na paisagem existente, principalmente a segmentação da malha urbana convencional através do cercamento por muros, e a constituição de áreas verdes e de lazer exclusivos, estes empreendimentos constituem um heterogêneo conjunto de produtos imobiliários rotulados imprecisamente como "Condomínio Fechado", que envolve desde pequenos nichos urbanos a enormes bairros nas partes suburbanas da metrópole. Em comum há somente a figura principal da habitação unifamiliar, seja isolada em um lote seja em renques de habitações geminadas.

Este tipo de empreendimento conquistou um público consumidor antes atendido pelos lançamentos em prédios de apartamentos, que desde a década de 1970 concentravam as mais atrativas opções de moradia em São Paulo em termos de custo e benefício. A idéia de morar em condomínio foi maciçamente difundida a partir dos empreendimentos de apartamentos, as primeiras experiências de produção de moradias em larga escala na metrópole paulistana'.

O lançamento dos empreendimentos de condomínios horizontais aproveitou-se em parte do fato desse padrão de moradia - a casa unifamiliar - ser bem conhecido pelo consumidor. $\bigcirc$ condomínio horizontal espalhou-se no período de 1985-95 e 1995-05 pelo território paulistano também aproveitando as experiências iniciais e comercialmente bem sucedidas em áreas suburbanas, em loteamentos como a Granja Viana e Alphaville.

Ainda que inseridos em um mercado residencial estreito e povoado por pequenas empresas oferecendo imóveis em praticamente todas as regiões da metrópole, com margens mínimas de retorno do investimento, os empreendimentos horizontais em condomínios foram vistos como uma opção que oferecia oportunidades com bom desempenho comercial. Desde meados de 1980, o mercado imobiliário passou por significativos ajustes internos, em parte como resposta ao escasseamento de recursos para financiamento habitacional. Estes ajustes se expressaram principalmente na adoção de formas de autofinanciamento das empresas empreendedoras como solução ao conseqüente encarecimento do crédito e à ausência de instrumentos de captação de recursos mais sofisticados, principalmente aqueles conjuntamente ao mercado financeiro. O resultado disto foi o maior comprometimento dos empreendedores nos investimentos e um desempenho bastante instável do setor.

Nesse sentido, o que permitiu que o produto Condomínio Horizontal Fechado ganhasse presença significativa no mercado imobiliário nestas duas décadas, diante das incertezas de crescimento sustentado do segmento?

No final da década de 1980 parte do sucesso desse modelo deveu-se aos empreendimentos suburbanos mas somente na década seguinte foi registrado um importante estímulo que consolidaria este segmento de mercado: a autorização da implantação de condomínios horizontais 
residenciais no município de São Paulo em áreas de ocupação estritamente unifamiliar. Se antes os empreendimentos horizontais detinham bom desempenho comercial nas regiões distantes da área central, permitiu-se através desta intervenção que este modelo de condomínio fosse transplantado aos bairros de urbanização consolidada e potencialmente mais valiosos. As zonas que receberam esses empreendimentos conformavam um vasto "estoque" de terra "sub-aproveitada" para os empreendedores residenciais, em especial as zonas de uso $1^{2}$.

Este novo tipo de empreendimento imobiliário permitiu que um universo bastante amplo de consumidores de média e alta renda adquirisse a casa própria em patamares acessíveis à renda domiciliar, principalmente a partir da metade década de 1990, quando a estabilização da moeda garantiu um crescimento real dos salários. Para o empreendedor imobiliário, o crescimento deste nicho de mercado significou a abertura de novas possibilidades de investimento diante das turbulências enfrentadas pelo mercado de imóveis e a criação de uma tipologia residencial com expressiva liquidez.

Tratou-se, assim, da criação de um produto de baixo risco e que permitiu agir sobre o solo intra-urbano como no suburbano. $\bigcirc$ primeiro devolveu ao mercado produtivo os terrenos mais valorizados da cidade, o segundo permitiu alavancar novas áreas de investimento e trazer ao mercado um investidor imobiliário resistente aos investimentos de risco em modelos de negócio ainda não consolidados.

No bojo do sucesso comercial está a transformação da paisagem intra-urbana e da rural empreendida por um capital imobiliário, responsável pela criação de empreendimentos residenciais de porte significativo. Concebidos como "organismos" urbanísticos independentes do restante do tecido, estes empreendimentos respondem a códigos de uso e ocupação do solo e permitem o usufruto exclusivo de um ambiente quase andrógeno, nem urbano nem rural. Neste artigo faremos menção a três tipos principais de condomínios: os suburbanos (fig. 1), os intra-urbanos de borda (Figura 2) e os intra-urbanos de meio (Figura 3).

A seguir apresentaremos periodização da evolução do crescimento desses empreendimentos na região metropolitana e, mais à frente, as suas principais características morfológicas de modo a apontar as principais características formais que estão vinculadas ao amadurecimento conceitual deste produto imobiliário e à sua aceitação por parte do mercado consumidor. Falar do impacto destas estruturas na paisagem sugere alguns meios de compreensão de um fenômeno que, senão inédito, é um dos motores da dispersão da mancha urbana da região metropolitana.

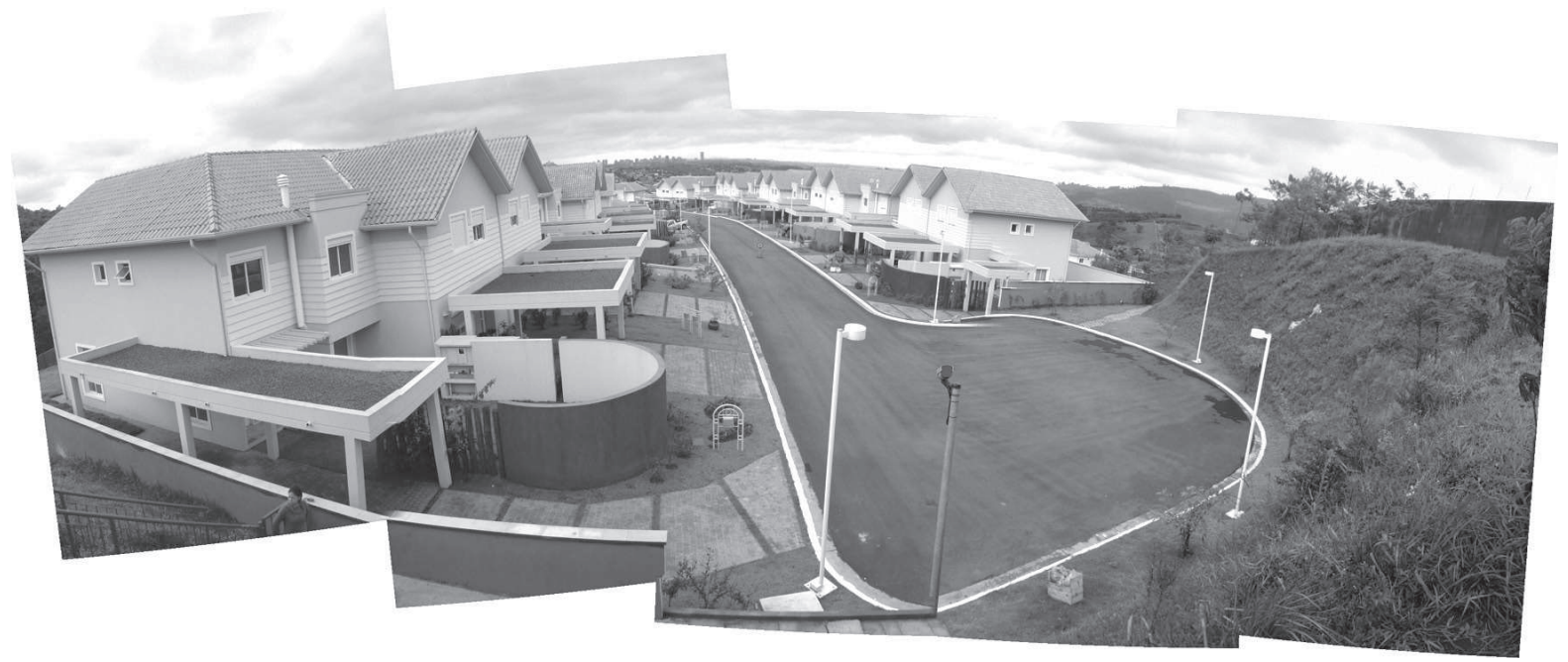

Figura 1: Condomínios suburbanos. Localizados nas partes rurais dos municípios, esses empreendimentos, geralmente, configuram-se como grandes empreendimentos residenciais, planejados ou não por um mesmo empreendedor. Estão distantes, em média, cerca de 30 km do centro histórico de São Paulo.

Crédito: João Lemos 

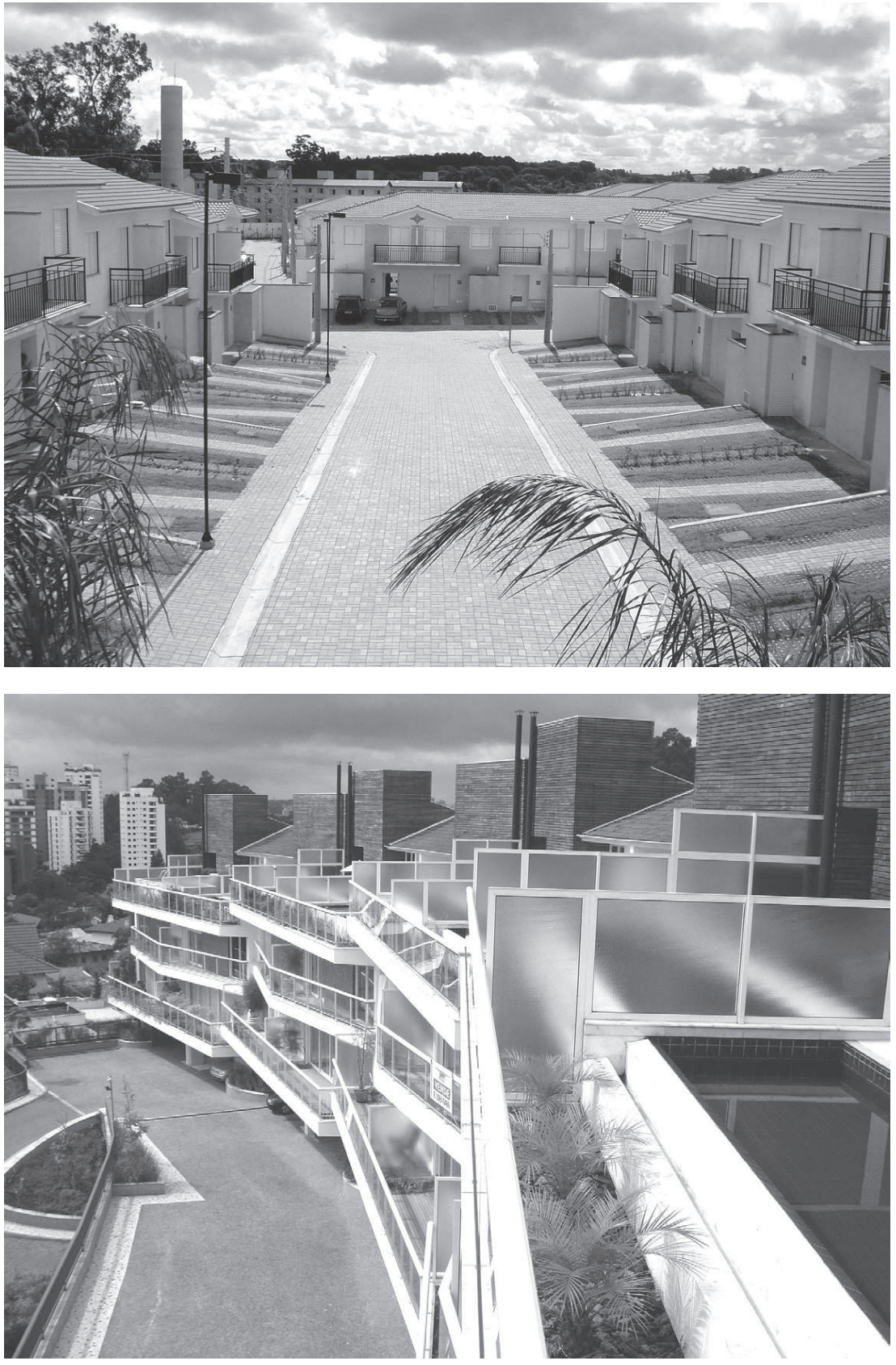

Figura 2: Condomínios intraurbanos de borda. Tratase dos empreendimentos localizados nos limites entre as áreas urbanas e rurais do município, em especial nas partes de dispersão urbana. Geralmente a existência de fartas glebas permite que esses empreendimentos alcançem expressiva área construída e um número significativo de unidades residenciais. Distanciam-se cerca de $15 \mathrm{~km}$ do centro da capital Crédito: João Lemos

Figura 3: Condomínios intra-urbanos de meio. São aqueles localizados em áreas de urbanização consolidada, com pouca disponibilidade de terrenos livres ou restrições urbanísticas que condicionam as dimensões e o número das unidades para os menores níveis registrados na metrópole Crédito: João Lemos

\section{Evolução e consolidação}

De forma geral, a expansão do condomínio horizontal na região metropolitana de São Paulo nas duas últimas décadas tendo como parâmetro a difusão desta tipologia em três etapas:

1. A primeira é caracterizada pelos primeiros núcleos implantados em regiões classificadas como suburbanas ${ }^{3}$, acessíveis somente através de automóveis e destinadas a um público-alvo na faixa de renda média-alta. Os residenciais Alpha e Tamboré, em Barveri, são a expressão mais bem acabada desse momento, com empreendimentos gerados a partir de grandes parcelamentos de glebas, a cargo de um capital incorporador, e responsáveis pela atração e desenvolvimento de atividades comerciais e terciárias.

2. A segunda se inicia em meados da década de 1990, quando foi autorizada a implantação de condomínios intra-urbanos em terrenos onde se permitia somente a ocupação por lotes de residências unifamiliares isoladas. A "Lei de Vilas" de 1994, como ficou conhecida, foi criada na gestão do prefeito Paulo Maluf e criou uma oportunidade para que se investisse nas zonas 
de uso 1 (Z1) até então congeladas em termos de ocupação, que thes garantia quase que perpetuamente a configuração de bairro jardim. No final da década, o sucesso do produto "Condomínio Horizontal " favoreceu a disseminação da tipologia inicial em inúmeras outras zonas de uso ${ }^{4}$. A demanda antes direcionada aos tipos suburbanos encontrou nas "vilas" uma alternativa urbana e economicamente viável para diversas faixas de renda. Nas áreas suburbanas onde se concentraram os maiores investimentos, por sua vez, consolidou-se os mercados imobiliários locais com a ampliação do estoque de terras pela incorporação de extensas glebas vizinhas. Novos empreendimentos foram desenhados já tendo como referencial as técnicas de promoção adotadas nos condomínios intra-urbanos, principalmente os cenários temáticos nos espaços internos através de projetos arquitetura e paisagismo integrados.

3. Ao final daquela década ocorreu um terceiro momento de expansão, em que o produto suburbano foi "reinventado" de modo a conter a concorrência que agora vinha das áreas intra-urbanas. Adaptações nas estratégias de investimento marcaram o surgimento dos novos empreendimentos, agora promovidos por um capital direcionado tanto à incorporação dos terrenos quanto à construção das casas. Se no primeiro momento os empreendimentos estiveram à cargo de pequenas e médias empresas de incorporação e construção, nesta etapa registrase a atuação de empresas com maior capacidade de investimento e gerenciamento. Os novos condomínios passaram a ser desenhados impreterivelmente com amenidades internas, como áreas de clube e serviços internos, "diferenciais", como áreas de "preservação ambiental", e geralmente vendidos com as casas já construídas, com arquitetura e projetos paisagísticos realizados por profissionais contratados pelos empreendedores de modo a serem criados cenários paisagísticos atrativos aos compradores, mascarando-se por vezes a exigüidade real das habitações e dos espaços livres condominiais. Nas partes intra-urbanas a tipologia atingiu um amplo universo de consumidores ao ser implementada em praticamente todos os bairros da capital e está em permanente crescimento, ao contrário dos demais segmentos residenciais do mercado.

Na etapa atual (2006), o trunfo dos empreendedores é a reinvenção do condomínio suburbano tendo como parâmetro a experiência do condomínio intra-urbano. Os apelos de uma arquitetura que remete aos empreendimentos suburbanos norte-americanos e os espaços livres equipados com programas de lazer intensivo passaram a ser promovidos em empreendimentos consideravelmente mais compactos e, não raro, com menos equipamentos de lazer que nas vilas intra-urbanas. Os intra-urbanos, por sua vez, passaram a oferecer áreas livres e amenidades antes restritas aos tipos suburbanos, principalmente nos empreendimentos situados em amplas glebas, geralmente nas bordas da região metropolitana e são produzidos para praticamente todas as faixas de renda e bairros do município de São Paulo.

\section{O ambiente externo}

Os "condomínios fechados" são usualmente implantados em locais com perfil censitário mais próximo ao do público-alvo do empreendimento, principalmente no que diz respeito à renda da população local, muito embora as unidades residenciais sejam oferecidas em patamares invariavelmente inacessíveis aos moradores anteriores. Seja nas partes suburbanas seja nas intra-urbanas, os empreendedores buscam conciliar o empreendimento a um determinado perfil da região de investimento.

Esta certa "dependência" entre o condomínio e seu entorno restringe-se, contudo, a esse aspecto; para o empreendedor, o objetivo central é a concepção de um ambiente fundamentalmente independente em termos urbanísticos do entorno próximo. Para tanto, os planejadores dos empreendimentos obedecem a certos requisitos de localização do empreendimento de modo a tornar tal "independência" funcional possível. Assim, a característica principal da localização do empreendimento é a proximidade aos principais eixos viários metropolitanos, 
de forma que estejam conectados aos locais de consumo e trabalho da região metropolitana. Todos os condomínios observados nessa pesquisa estão localizados próximos a vias de rápida velocidade. Outra requisito que determina a escolha pelo sítio é a oferta de glebas vazias. Quando há uma significativa região na qual há terrenos adequados próximos a troncos de circulação metropolitana, o afluxo de condomínios é certo tal qual a rápida concentração de empreendimentos similares.

A urbanização promovida nos terrenos vazios apresenta uma estrutura bastante simples. Trata-se geralmente de um loteamento ou parcelamento estruturado em uma via de distribuição principal onde os condomínios são implantados diretamente ou em pequenas vias que a ela convergem. No caso específico dos condomínios intra-urbanos, há a dependência por um tecido urbanos com lotes disponíveis e passíveis de remembramento aos adjacentes. Isto determina uma ocupação mais dispersa no tecido, ainda que na escala da zona urbana constituam-se como expressivas manchas concentradas. Nos casos suburbanos e nas bordas urbanas há a realização de novos tecidos, ao contrário nos de meio, que se configuram como fragmentos diferentes e dispersos. Nestas áreas, os condomínios estão predominantemente localizados em zonas estritamente residenciais já consolidadas.

Existe, também, um padrão de proximidade junto a equipamentos públicos nos casos intra-urbanos, geralmente em distâncias semelhantes aos estabelecimentos de consumo. Nos condomínios intra-urbanos de meio e nos suburbanos, pode-se encontrar inclusive equipamentos privados no entorno próximo.

condomínio horizontal configura-se como um produto bastante flexível às condicionantes dos tecidos urbanos existentes quando atendidas as condições sócio-econômicas da vizinhança e de acessibilidade. É justamente essa capacidade de aglutinar vantagens de localização que permite um afluxo de moradores com perfil de renda diferente ao do local. Essa dinâmica ganha destaque nos locais onde há concentração de lançamentos semelhantes.

\section{A paisagem interna}

A organização espacial e funcional dos condomínios permite a constituição de uma unidade urbana autônoma que pouco se relaciona formalmente e funcionalmente com o entorno imediato. Internamente, é estruturada por setores isolados. Externamente, é isolada pelos muros e se conecta ao tecido urbano somente por um ponto de ligação.

Os condomínios são estruturados segundo o princípio de separação das atividades internas. O uso residencial é o predominante e a ele estão associados às atividades de lazer e de apoio (administração, segurança, etc.), que se localizam adjacentes às residências. Este padrão permite não só a maximização da ocupação, mas também a hierarquização das atividades em espaços bem delimitados.

O ambiente original é em geral modelado para acomodar a implantação. Cada tipo possui um esquema de acesso entre as vias e as residências com domínios privados e os de uso coletivo característicos. Os movimentos de terra e o desmatamento da cobertura arbórea acabam por eliminar, em geral, as características originais do meio ambiente. Nos primeiros condomínios suburbanos encontram-se os exemplos mais expressivos dos impactos ao suporte ambiental. As estruturas viárias em rede, bastante empregadas nesses empreendimentos (ver Figura 4), promovem grandes superfícies impermeáveis por vias de tráfego e reduzidas áreas livres. Nas partes intra-urbanas, promovidas a partir da segunda fase e principalmente desde a terceira, encontram-se estruturas baseadas em sistemas de circulação em forma de "espinha de peixe" (ver Figura 5) e por disposições das residências em forma de pátio, mais compactas e que permitem maiores áreas livres. 


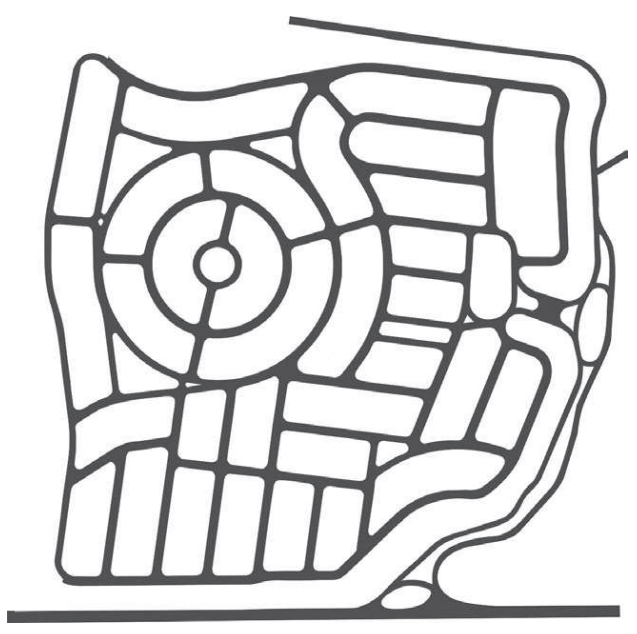

Figura 4: Estruturas em forma de rede. As vias internas estão integradas em um circuito fechado, com um único ponto de conexão com a área externa Crédito: João Lemos

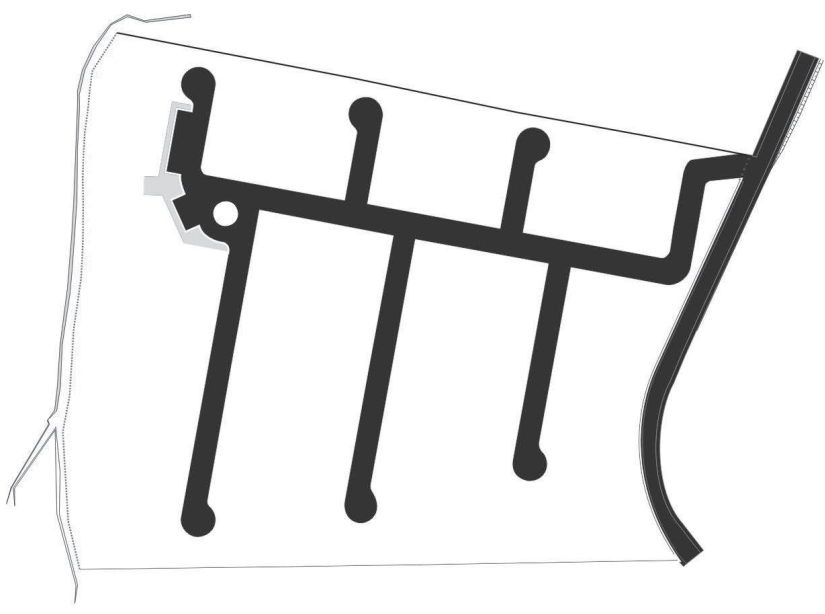

Figura 5: Estrutura tipo "espinha de peixe". Uma via de tráfego principal interliga a portaria do empreendimento às demais vias que dela se originam Crédito: João Lemos

Um aspecto importante nos condomínios construídos atualmente é a mudança do papel dos empreendedores imobiliários na configuração dos empreendimentos. Ao assumirem as etapas de construção das residências, os empreendedores passaram a controlar as características estéticas das residências de modo integrado ao do restante dos espaços comuns. Profissionais especializados ganharam espaço na concepção conjunta entre os lotes e as áreas livres, em especial os arquitetos paisagistas. Todos os condomínios apresentam casas com quintais e jardins com projeto arquitetônico pré-definido e construído, além de projeto paisagístico integralmente implantado; as áreas de lazer possuem um número maior de equipamentos, que são disponíveis em partes separadas do condomínio para sugerirem ser verdadeiros clubes internos. Com isso, os empreendedores fornecem aos compradores um produto imobiliário concebido de modo único para o uso exclusivo.

\section{A paisagem exclusiva}

Este tipo de empreendimento foi idealizado inicialmente como indutor de crescimento do mercado imobiliário em regiões da metrópole onde se pudesse explorar um novo nicho de mercado. A gênese deste processo ocorre na região oeste da metrópole, em locais onde a natureza supostamente estava intocada pelo modo de ambiente construído urbano. Sua motivação era a garantia de uma "exclusividade" que permitiria usufruir uma melhor qualidade de vida através da casa própria construída em lote unifamiliar.

Na consolidação desta idéia surge o condomínio como um empreendimento adequado aos interesses de agentes imobiliários, de consumidores e do poder público na promoção de um modo de vida que possa ser reproduzível ora nas áreas de expansão da metrópole, ora nos vazios ou pontos consolidados de áreas intra-urbanas.

Este movimento de distanciamento das áreas urbanas não é uma idéia nova, remete às tentativas de remodelação da cidade industrial já em fins do século XIX. Porém, vamos verificar no momento da consolidação comercial deste tipo de empreendimento, no final da década de 1990, que o condomínio fechado atinge um patamar de produção similar aos demais tipos de empreendimentos residenciais justamente na área intra-urbana, desde que foi autorizado a se instalar nas zonas mais valiosas da cidade de São Paulo. É, pois, no mínimo curioso que esta proposta de fuga dos problemas urbanos tenha encontrado quase duas décadas depois sua 
consolidação comercial no próprio interior dos centros urbanos. Ao recriar a "Vila", o mercado imobiliário consegue redirecionar a demanda de consumidores por um ambiente "renovado", "exclusivo" e "seguro" das bordas da metrópole para a urbe, pois nesse momento revelou-se ser indiferente morar dentro ou fora do da zona urbana, desde que fosse oferecida, fundamentalmente, a possibilidade de morar em uma casa própria com o máximo possível de amenidades para uso exclusivo e com vantagens de localização, principalmente de mobilidade rápida para o restante urbano. $\bigcirc$ trunfo do produto condomínio fechado não é, portanto, a promoção de uma vida junto à natureza, tão difundida pelos promotores de venda. Sua receita para equacionar o problema foi fixar-se em terrenos com menor custo de aquisição, contornando códigos de edificação que impossibilitavam erguer empreendimentos similares nas áreas urbanas e enfrentando o mesmo custo de edificação vertical a preço competitivo.

O produto Condomínio Horizontal Fechado agregou as qualidades da casa com jardim e garagem individuais, maior área útil e preço similar ao de um apartamento, compensando os custos de transporte, dada a maior distância dos centros urbanos. Mas quando se planeja a transposição deste tipo de empreendimento para o ambiente intra-urbano, o poder público é chamado a modificar profundamente a legislação de uso e ocupação do solo consagrada para poder absorver o modelo consagrado nas bordas da metrópole. A Lei do Zoneamento, de 1972, restringia o aparecimento de novas tipologias de edificação urbana e desestimulava até mesmo a reprodução de tipologias conhecidas, como a vila residencial, que entre 1972 e 1994 praticamente desapareceu da produção imobiliária de São Paulo.

A transposição do novo tipo de condomínio para o mercado intra-urbano, portanto, encontrou dificuldades de execução imediata, mas a demanda das classes médias, em busca de preços compatíveis ao seu poder de compra, constituiu um mercado promissor e um objetivo de curto prazo para as iniciativas dos empreendedores. A "Lei de Vilas", de 1994, foi uma resposta desenhada pelos agentes privados para esse novo tipo de ocupação do solo urbano. $\bigcirc$ fim das restrições ao condomínio horizontal na zona mais restritiva do antigo zoneamento, a Z1, deu início a um novo período de expansão do condomínio fechado. Se o código de zoneamento respondia pelo engessamento do mercado imobiliário em termos de inovação tipológica, podemos dizer que a "Lei de Vilas" veio eliminar as barreiras aos terrenos mais valiosos da cidade. A "Vila" que aí surge não é a mesma do início do século XX, mas uma forma de condomínio horizontal passível de ser implantada em lotes antes destinados a uma única casa.

Concluindo, retomamos a idéia de que o produto Condomínio Horizontal Fechado é simultaneamente fruto das transformações ocorridas na metrópole e de sua conjuntura econômica. É também uma estrutura espacial que introduz transformações nos fluxos de circulação, localização de riqueza e de população urbana ao gerar novos tecidos na região de influência. Simultanea-mente, é um produto desse ambiente por ser formatado de modo a potencializar os ganhos do capital imobiliário e atender aos interesses de classe de usufruir exclusivamente as porções do território mais valorizadas.

\section{Notas}

(1) $\bigcirc$ mercado de casas unifamiliares na mancha urbana, contudo, não foi reduzido com a difusão dos edifícios de apartamentos. Ainda em 2006 a residência em forma de casa representa cerca de $40 \%$ da produção formal na cidade de São Paulo, conforme levantamento realizado pelo autor no cadastro de aprovação de novas plantas para uso residencial pela prefeitura de São Paulo no período de 2004 a 2005 (ver São Paulo (cidade); Sehab (Secretaria Municipal de Habitação, 2005).

(2) Neste artigo as menções às zonas de uso legais referem-se àquela instituída em 1973 pela Lei do Zoneamento, a qual abrange o universo de estudos de caso desta pesquisa.

(3) Para efeito de análise, as regiões ditas "suburbanas" são aquelas localizadas nas zonas rurais dos municípios vizinhos a São Paulo, em geral distantes cerca de 30 km do centro histórico da capital. 
(4) Os condomínios intra-urbanos estão subdivididos nesta pesquisa em dois tipos: condomínios "de meio" e "de borda". Enquanto os primeiros se referem àqueles localizados em áreas de transição às zonas rurais, geralmente junto dos limites municipais, os últimos são aqueles localizados em porções de urbanização consolidada, circunscrita a um perímetro de cerca de $15 \mathrm{~km}$ desde o centro histórico da cidade de São Paulo.

\section{Bibliografia}

AlBERTO, Carlos; MOURA, Solange Aragão. As antigas e as novas vilas de São Paulo: Conceituação e estudos de caso. Paisagem e Ambiente: Ensaios, São Paulo, n. 12, p. 29-68, 1999.

ALENCAR, Cláudio Tavares de. O comportamento macroeconômico brasileiro e os impactos no mercado residencial na cidade de São Paulo. In: 10 SEMINÁRIO LARES - LATIN AMERICAN REAL ESTATE SOCIETY. In: 1999, São Paulo, Anais(CD-ROM), São Paulo, 1999.

ARAGÃO, Solange Moura Lima de. Espaços livres urbanos: A produção da caracterização das áreas de uso comum dos conjuntos de edifícios de apartamento paulistanos (1990-2004). 2005. Tese (Doutorado) - Faculdade de Arquitetura e Urbanismo, Universidade de São Paulo, São Paulo, 2005.

ARENDT, Randall. Conservation design for subdivisions. Washington: Island Press, 1996.

BIDERMAN, Ciro. Forças de atração e expulsão na Grande São Paulo. 2001. Tese (Doutorado) - Fundação Getúlio Vargas, Escola de Administração de Empresas de São Paulo, São Paulo, 2001.

BOTELHO, Adriano. Relações entre o financiamento imobiliário e a produção do espaço na cidade de São Paulo: Casos de segregação e fragmentação espaciais. Scripta Nova, Barcelona, v. IX, n. 194, p. 18, 2005.

BRASIL, IBGE (Instituto Brasileiro de Geografia e Estatística). Censo Demográfico 2000. Disponível em: <http:// www2. ibge.gov.Br/pub/censo/censodemograsico2000>.

CAMPOS, Ana Cecília Mattei de Arruda. Por dentro dos muros: As ações programadas e o processo de estruturação dos espaços livres. Memorial de passagem para doutorado. São Paulo: FAUUSP, 2005.

COTIA (Cidade); PRO-COTIA. Foto aérea do município de Cotia - ano 2003. Cotia, 2003.

EMBRAESP (Empresa Brasileira de Estudos de Patrimônio). Empreendimentos na região metropolitana - 22/7 a 8/9/2002. São Paulo, 2004.

GEGRAN/ Sistema Cartográfico Metropolitano da Grande São Paulo. Lotscan: Matricial de edificações, lotes, quadras, logradouros e topografia. São Paulo, 1973.

GREATER LONDON COUNCIL. Introduction to housing layout. Londres: Architectural Press, 1978.

MARCUSE, Peter. Enclaves, sim; guetos, não: A segregação e o estado. Espaço e Debates, São Paulo, n. 45, p. 24-33, 2004.

MEYER, Regina Maria Prosperi; GROSTEIN, Marta Dora; BIDERMAN, Ciro. São Paulo metrópole. São Paulo: Edusp/Imprensa Oficial do Estado de São Paulo, 2004.

MONETTI, Eliane. Demanda por recursos para financiar a comercialização do produto habitacional na cidade de São Paulo. In: 10 SEMINÁRIO LARES - LATIN AMERICAN REAL STATE SOCIETY, 1999, São Paulo. Anais... (CD-ROM), São Paulo, 1999

NETO, Hélio Mítica. Caracterização do processo de expansão da mancha urbana na cidade de Campinas: A rodovia Dom Pedro I como o novo eixo articulador da região metropolitana. Memorial de passagem para doutorado. São Paulo: FAUUSP, 2005.

PELLEGRINO, Paulo Renato Mesquita. Paisagens temáticas. 1995. Tese (Doutorado) - Faculdade de Arquitetura e Urbanismo, Universidade de São Paulo, São Paulo, 1995.

RIBEIRO, Luiz César de Queiroz. Dos cortiços aos condomínios fechados: As formas de produção da moradia na cidade do Rio de Janeiro. Rio de Janeiro: Civilização Brasileira, 1996.

ROCHA LIMA JÚNIOR, João. Planejamento do produto no mercado habitacional. Boletim Técnico da Escola Politécnica da USP. Departamento de Engenharia de Construção Civil. BT/PCC/1 10, São Paulo: Edusp, 1993.

Instrumentos de investimentos em empreendimentos habitacionais no Brasil: A questão estrutural. Boletim Técnico da Escola Politécnica da USP. Departamento de Engenharia de Construção Civil. BT/PCC/354, São Paulo: Edusp, 2004. 
ROMERO, Auro Moreno. Alphaville: Ilusão do paraíso. 1997. Dissertação (Mestrado) - Faculdade de Filosofia, Letras e Ciências Humanas. Departamento de Geografia, Universidade de São Paulo, São Paulo, 1997.

SALGADO, Elisabeth Carvalho de Oliveira. O loteamento residencial fechado no quadro das transformações da metrópole de São Paulo. São Paulo: FAUUSP, 2000.

SÃO PAULO (Cidade); SEHAB (Secretaria Municipal de Habitação); DEPARC (Departamento de Regularização de Parcelamento do Solo). Foto aérea do município de São Paulo - Ano 2000. São Paulo, 2000.

SÃO PAULO (Cidade); SEHAB (Secretaria Municipal de Habitação). Cadastro de plantas aprovadas - 2002 e 2005. São Paulo, 2005. Disponível em: <http://www2.prefeitura.sp.gov.br/secretarias/habitacao/provacao_edificacoes/0001>.

SÃO PAULO (Cidade); Sempla/Deinfo (Secretaria Municioal de Planejamento Urbano / Departamento de Informações). Estabelecimentos comercias e serviço distrito. escala 1:100 000, 2005.

SEADE (Fundação Sistema Estadual de Análise de Dados); IBGE (Instituto Brasileiro Geográfico e Estatístico). Índice paulista de vulnerabilidade social. São Paulo, 2005. Disponível em: < http://www.al.sp.gov.br/web/ipvs/index_ipvs.htm>.

TOPALOV, Christian. La urbanización capitalista. Cidade do México: Editorial Edicol, 1979.

VALENTE, Edson. Itaquera é líder em lançamentos de casas. Folha de São Paulo, São Paulo, 19 dez. 2004. 